\title{
Free amino acid contents of selected Ethiopian plant and fungi species: a search for alternative natural free amino acid sources for cosmeceutical applications
}

\author{
Birhanu Nigusse Kahsay ${ }^{1}$. Jörg Ziegler ${ }^{2}$ Peter Imming ${ }^{3}$ - Tsige Gebre-Mariam ${ }^{1} \cdot$ Reinhard H. H. Neubert ${ }^{4}$. \\ Lucie Moeller ${ }^{3,5}$ (1)
}

Received: 9 July 2020 / Accepted: 20 May 2021 / Published online: 9 June 2021

(c) The Author(s) 2021

\begin{abstract}
Free amino acids (FAAs), the major constituents of the natural moisturizing factor (NMF), are very important for maintaining the moisture balance of human skin and their deficiency results in dry skin conditions. There is a great interest in the identification and use of nature-based sources of these molecules for such cosmeceutical applications. The objective of the present study was, therefore, to investigate the FAA contents of selected Ethiopian plant and fungi species; and select the best sources so as to use them for the stated purpose. About 59 different plant species and oyster mushroom were included in the study and the concentrations of 27 FAAs were analyzed. Each sample was collected, lyophilized, extracted using aqueous solvent, derivatized with Fluorenylmethoxycarbonyl chloride (Fmoc-Cl) prior to solid-phase extraction and quantified using Liquid Chromatography Electrospray Ionization Tandem Mass Spectrometric (LC-ESI-MS/MS) system. All the 27 FAAs were detected in most of the samples. The dominant FAAs that are part of the NMF were found at sufficiently high concentration in the mushroom and some of the plants. This indicates that FAAs that could be included in the preparations for the management of dry skin condition can be obtained from a single natural resource and the use of these resources for the specified purpose have both economic and therapeutic advantage in addition to fulfilling customer needs.
\end{abstract}

Keywords Free amino acids $\cdot$ Natural moisturizing factors $\cdot$ Cosmeceuticals $\cdot$ Ethiopian plants $\cdot$ Oyster mushroom

\section{Introduction}

Handling editor: J. Metcalf.

Lucie Moeller

lucie.moeller@ufz.de

1 Department of Pharmaceutics and Social Pharmacy, School of Pharmacy, College of Health Sciences, Addis Ababa University, P. O. Box 9086, Addis Ababa, Ethiopia

2 Department of Molecular Signal Processing, Leibniz Institute of Plant Biochemistry, Weinberg 3, 06120 Halle (Saale), Germany

3 Department of Medicinal Chemistry and Clinical Pharmacy, Martin Luther University Halle-Wittenberg, Kurt-Mothes-Str. 3, 06120 Halle (Saale), Germany

4 Institute of Applied Dermatopharmacy, Martin Luther University Halle-Wittenberg, Weinbergweg 23, 06120 Halle (Saale), Germany

5 Department Centre for Environmental Biotechnology, Helmholtz Centre for Environmental Research, Permoserstr. 15, 04318 Leipzig, Germany
Amino acids, often called "the building blocks of life", are primary metabolites which play a vital role in nutrition and health maintenance (Leuchtenberger et al. 2005; Mueller and Huebner 2003). They are used as ingredients in cosmetic and pharmaceutical products and as special nutrients in the medical field (Ikeda 2003; Park and Lee 2008). They are commonly employed in transfusions (Naylor et al. 1989; Louard et al. 1990; Stoimenova et al. 2013), in the manufacture of artificial sweeteners such as aspartame and as intermediate precursors for the production of antibiotics (Newsholme et al. 1985; Tang et al. 1994; Demain 2000; Garg et al. 2008). Amino acids, individually or in group, are also very important for the treatment of many disease conditions (Meletis and Barker 2005; Wu 2009; Lee and Kim 2019; Takaoka et al. 2019).

Free amino acids (FAAs) are also indispensable for healthy skin. They constitute the largest component ( 40\%) of the so-called natural moisturizing factor (NMF) (Jokura 
et al. 1995) and are very important in maintaining the moisture balance of skin. The most abundant FAAs within the NMF are L-serine (Ser) ( 36\%), L-glycine (Gly) ( 22\%) and L-alanine (Ala) ( 13\%) (Caspers et al. 2001). Citrulline (Cit), ornithine (Orn), histidine (His) and arginine (Arg) all account for 6-8\%. In another study by Burke et al. (1966), Ser, Gly, Cit, Ala, His, and threonine (Thr), in that order, are the dominant FAAs in the horny layer of human skin and account for as much as $80 \%$. Methionine (Met), cysteine (Cys), and tryptophan (Try) are present in smallest concentrations; and proline (Pro) is obscured because of the large amount of Cit masking its presence. Twenty-three (23) FAAs were detected in human corneocytes of 4 different study groups in a study by Hussain et al. (2019) at different concentrations. The level of NMFs including FAAs can decline in dry skin conditions due to many disease conditions such as atopic dermatitis, ichthyosis vulgaris, psoriasis, and age in addition to environmental conditions (Verdier-Sévrain and Bonté 2007; Kwan et al. 2012; Takada et al. 2012). The best way to overcome such disease condition seems to be the delivery of the major components of the NMF to the human skin in the form of moisturizers (Arezki et al. 2017). Even though much research work has not yet been done, FAAs have definitely a potential use in the cosmeceuticals.

FAAs for food, cosmeceutical and pharmaceutical applications can be obtained in four different methods, namely extraction (from natural resources), chemical synthesis, enzymatic synthesis, and fermentation (Leuchtenberger et al. 2005; Ikeda 2003). Despite the advancements in chemical synthesis and biotechnology, the need for herbal medicines is still at the top indicating the extraordinary relation between human beings and herbs, an almost mystical interdependence. As reported by the world health organization (WHO), about $80 \%$ of the total world population uses herbal medicines as their first-line primary health-care (Nagalingam 2017; Srivastava et al. 2019; Sharma et al. 2019). This resurgence of public interest in herbal remedies has been attributed to several factors including but not limited to the following: (a) herbal medicines are practically a mixture of many bioactive chemicals that can act synergistically (Sandberg and Corrigan 2001; Segneanu et al. 2017); (b) they might be more effective as compared to similar substances obtained through chemical synthesis (Thornfeldt 2005); (c) they are economically feasible and can be used by people at all economic levels; (d) they are preferable in terms of safety (side effects), contraindications and interactions with other substances (Segneanu et al. 2017); and (e) they have superior structural diversity, complex structure and multiple stereo centers (Phillipson 2001). There is also belief that herbal medicines are superior to manufactured products. In the cosmetic industry, herbal cosmeceuticals are the modern trend in the field of health, beauty and fashion; and there is a greater interest to use herbal materials. Herbal medicines are also highly believed to lead people to self-medication (Bandaranayake 2006). In addition to the reasons mentioned above, in cosmeceutical preparations that could contain the major constituents of the NMF (FAAs), use of a single natural source has a lot of economic advantage than using FAAs produced individually through any of the other options.

Understanding their benefits, the WHO has been working toward increasing the use of herbal medicines (WHO 2013) and currently about $25 \%$ of new drugs approved by Food and Drug Administration (FDA) and/or the European Medical Agency (EMA) are directly or indirectly plant based (Newman and Cragg 2012; Calixto 2019). Hence, research on plant-based bioactive molecules is among the top research topics in the pharmaceutical sector (Segneanu et al. 2017; Azmir et al. 2013; Chikezie et al. 2015). Due to such reasons, many countries have been extensively using their plants for pharmaceutical and cosmeceutical applications (Ji et al. 2017; Ruhsam and Hollingsworth 2018).

Ethiopia, a country endowed with a diverse biological resources and home of about 6500-7000 species of higher plants of which $12 \%$ are endemic, is one of the six regions rich in plant biodiversity (Berhan and Egziabher 2009) and these can be of course alternative sources of FAAs. Use of such sustainable and natural ingredients for cosmeceutical applications has a lot of benefits to the population in fostering sustainability and natural remedial approaches. Moreover, most of the major constituents of the NMF can be obtained from a single plant and this has superior advantage than the use of individual FAAs obtained through different options.

The objective of the present study was, therefore, to analyze the FAA contents of Ethiopian plants and mushroom and thus to identify those natural resources with highest amount of FAAs that can further be used for cosmeceutical applications in the management of dry skin conditions.

\section{Materials and methods}

\section{Materials}

A total of 60 plant and fungi species were collected from Gullele Botanical Garden and local supermarkets found in Addis Ababa, Ethiopia. All the plant and mushroom species were authenticated by the Ethiopian Biodiversity Institute, Addis Ababa, Ethiopia. Plant varieties such as cereals, leguminous plants, vegetables, fruits, spices and tea plants were included. In addition to the commonly used food items, attention was given to some indigenous aloe plants. One of the most common mushrooms found in Ethiopia, the Pleurotus ostreatus (Jacq. ex Fr.) P. Kumm., was also included in the study. Moreover, residuals from food processing such as the peals of fruits were also included. Prior consideration 
was given that the selected species can be cultivated and harvested at a rate conducive to production demands.

All the L-amino acid standards (Ala, Cys, Ser, Pro, His, Cit, Gly, Orn, Thr, Trp, Arg, Met, aspartate (Asp), glutamate (Glu), asparagine (Asn), glutamine (Gln), $\gamma$-aminobutyric acid (GABA), leucine (Leu), isoleucine (Ile), valine (Val), phenylalanine (Phe), lysine (Lys), $O$-acetylserine, oxyproline, methionine oxide, taurine (Tau), and tyrosine (Tyr)) and the internal standard, norvaline, were purchased from Sigma-Aldrich. Reagent grade $n$-pentane, sodium borate, and 9-fluorenylmethoxycarbonyl chloride ( $\mathrm{Fmoc}-\mathrm{Cl})$ were also commercial products from Sigma-Aldrich. HPLC grade methanol and acetonitrile were used and these were purchased from Roth (Karlsruhe, Germany). Ultrapure water (resistivity $18.2 \mathrm{M} \Omega$ ) purified by TKA X-CAD ultrapure water purification system (Thermo Fisher Scientific, Waltham, MA, USA) was used at all steps where water was required. Chromabond ${ }^{\circledR}$ Multi 96 filter plates and Chromabond ${ }^{\circledR}$ Sorbent HR-X were from Macherey-Nagel (Düren, Germany). All other reagents were of analytical grade.

\section{Methodology}

The analysis of FAAs was conducted as per the method reported elsewhere (Ziegler et al. 2019). The procedure is briefly described in the following sections.

\section{Sample extraction}

Each sample was collected in triplicate and the collected samples were freeze dried (Alpha 2-4-LSC, Martin Christ Gefriertrocknungsanlagen GmbH, Germany). Five milligrams $(5 \mathrm{mg}$ ) of each of the lyophilized samples was weighed using dual range analytical balance (Model XA105, Mettler Toledo, USA) and transferred to a $2 \mathrm{~mL}$ Eppendorf tube. A steal bead of $5 \mathrm{~mm}$ in diameter was inserted to each Eppendorf tube and the samples were pulverized in a mixer mill (Model MM 301, Retsch GmbH, Germany) at $25 \mathrm{~s}^{-1}$ for $50 \mathrm{~s}$. Two hundred microliters $(200 \mu \mathrm{L})$ of extraction solvent [a mixture of water and $10 \mathrm{mM}$ norvaline $(1 \mathrm{~mL}: 5 \mu \mathrm{L})$ ] was added to each sample and the samples were mixed thoroughly for 20 min on a vortex (JK Janke and Kunkel IKA, model IKA VIBRAX-VXR). The samples were then centrifuged (Model 5415C, Eppendorf ${ }^{\circledR}$, Germany) at 10,000 $\times g$ for $5 \mathrm{~min}$ and the supernatant was transferred to a $1.5 \mathrm{~mL}$ Eppendorf tube. This solution was again centrifuged (Model $5415 \mathrm{C}$, Eppendorf ${ }^{\circledR}$, Germany) at $10,000 \times g$ for $5 \mathrm{~min}$ and the supernatant was transferred to a new $1.5 \mathrm{~mL}$ Eppendorf tube. This solution was stored in deep freezer at $-80{ }^{\circ} \mathrm{C}$ until the next process.

\section{Standard preparation}

Twenty millimolar $(20 \mathrm{mM})$ stock solution of each amino acid standard was prepared in ultrapure water. Five microliters $(5 \mu \mathrm{L})$ of each of the resulting solutions was transferred to a $2 \mathrm{~mL}$ Eppendorf tube and the resulting mixture was diluted to $500 \mu \mathrm{L}$ with the same solvent. Finally, serial standard solutions were prepared for each amino acids and the internal standard to get a final concentration of $0,2,4,8$, 16,64 and $128 \mathrm{pmol} / \mu \mathrm{L}$ after derivatization. These standard solutions were stored in deep freezer until the next step.

\section{Sample derivatization and processing}

After thawing at room temperature, $25 \mu \mathrm{L}$ of the standard and sample solutions were transferred to $1.5 \mathrm{~mL}$ Eppendorf tubes. Fifty microliters $(50 \mu \mathrm{L})$ of $0.5 \mathrm{M}$ sodium borate buffer $\mathrm{pH} 7.9$ and $100 \mu \mathrm{L} 6 \mathrm{mM}$ Fmoc-Cl solution (in acetone) were added to each solution and the resulting mixture was incubated for at least 5 min after mixing. Five hundred microliters $(500 \mu \mathrm{L})$ of $n$-pentane was added to each solution, mixed thoroughly, centrifuged (Model 5415C, Eppendorf $^{\circledR}$, Germany) at $10,000 \times g$ for $1 \mathrm{~min}$ and the upper (organic phase) was discarded. This step was repeated two more times. After the last extraction step and removal of the organic phase, the tubes were opened and allowed to stand in a fume hood for evaporation of any residual organic solvent.

\section{Solid-phase extraction}

Solid-phase extraction (SPE) was conducted using Chromabond Multi 96-well plate (Macherey-Nagel, Düren, Germany) containing $50 \mathrm{mg} /$ well HR-X-resin (Macherey-Nagel, Düren, Germany). First, the SPE plate was conditioned by $1 \mathrm{~mL}$ of methanol followed by $1 \mathrm{~mL}$ of water. In this and all subsequent steps, the liquid was passed through the resin by centrifugation at $500 \times g$ for 5 min using JS5.3 swingout rotor in an Avanti J-26XP centrifuge (Beckman Coulter, Fullerton, CA, USA). $500 \mu \mathrm{L}$ of $5 \%$ (v/v) acetonitrile was added to the sample and standard solutions mentioned in "Sample derivatization and processing". Then, the resulting solutions were quantitatively loaded onto the SPE plate, washed with $1 \mathrm{~mL}$ of water and the flow through was discarded after centrifugation. In the next step, $1 \mathrm{~mL}$ of methanol was added into the 96-deep well plate and eluted to a new block by centrifugation. Finally, the eluates were transferred from the 96-deep well block to $2 \mathrm{~mL}$ Eppendorf tubes, and allowed to evaporate under vacuum in an Eppendorf Concentrator (Model 5301, Eppendorf, Hamburg, Germany) at $45^{\circ} \mathrm{C}$ for $45 \mathrm{~min}$. Finally, the samples were centrifuged (Model $5415 \mathrm{C}$, Eppendorf ${ }^{\circledR}$, Germany) at $10,000 \times g$ for $10 \mathrm{~min}$ and the supernatant was transferred to the 96-well plate and the plate was placed in LC-MS/MS auto-sampler. 


\section{LC-ESI-MS/MS analysis}

Chromatographic separation was achieved using Agilent 1290 liquid chromatography system equipped with Zorbax Eclipse Plus C18 Rapid Resolution HD column $(2.1 \times 50 \mathrm{~mm}, 1.8 \mu \mathrm{m}$, Agilent). The column temperature was maintained at $30{ }^{\circ} \mathrm{C}$. Gradient elution with solvent A $(0.2 \% \mathrm{v} / \mathrm{v}$ acetic acid in water $)$ and solvent $\mathrm{B}(0.2 \% \mathrm{v} / \mathrm{v}$ acetic acid in acetonitrile) was used as mobile phase at a flow rate of $700 \mu \mathrm{L} / \mathrm{min}$. Solvent A was held constant at $75 \%$ for $0.3 \mathrm{~min}$ and decreased to $50 \%$ over the next $6.7 \mathrm{~min}$. Then, it was held at $2 \%$ over the next $0.7 \mathrm{~min}$ and increased to $75 \%$ for the next $0.4 \mathrm{~min}$. Ten microliters $(10 \mu \mathrm{L})$ and $4 \mu \mathrm{L}$ were injected in to the auto-sampler for the sample and standard solutions, respectively.

Detection was done using API 3200 Triple Quadrupole LC-MS/MS system equipped with an ESI Turbo Ion Spray interface, operated in the negative ion mode (AB Sciex). The ion source parameters were set as follows: curtain gas was used at a pressure of $30 \mathrm{psi}$. The ion spray voltage was $-4500 \mathrm{~V}$ and the ion source temperature was set at $350{ }^{\circ} \mathrm{C}$. Both the nebulizing and drying gas pressure were set at 50 psi. Triple quadrupole scans were acquired in the multiple reaction monitoring (MRM) mode with Q1 and Q3 set at "unit" resolution. Scheduled MRM was performed with a window of $90 \mathrm{~s}$ and a target scan time of $0.5 \mathrm{~s}$. The mass spectrum (MS) parameters describing the MRMs for each FMOC-Cl derivatized amino acid were as reported by Ziegler et al. (2019).

\section{Data analysis}

The data analysis was done by automatic integration using Analyst software. A calibration curve was constructed using the standard solutions and from the graph the slope of the regression line was determined. The concentration (conc) of each FAA in $\mathrm{nmol} / \mathrm{mg}$ was determined using the following equation and these results were converted to $\mathrm{mg} / \mathrm{g}$ : at varying concentrations (taurine (Tau), methionine oxide, $O$-acetylserine and oxyproline were analyzed but the results are not included in Table 1 as the concentrations were very low).

Oyster mushroom (Pleurotus ostreatus (Jacq. ex Fr.) P. Kumm.), a healthy food rich in protein, chitin, vitamins and minerals and which contains many bioactive molecules (Khan and Tania 2012), is ranked second among the important cultivated mushrooms in the world (Jose and Janardhanan 2000). In the present study, it had higher total FAA concentration $(400.01 \mathrm{mg} / \mathrm{g})$ as compared to all the tested samples (see Table 1) and the presence of such molecules may contribute to its characteristic flavor (Mau et al. 1998). The concentration of most of the FAAs was greater than $15.00 \mathrm{mg} / \mathrm{g}$ which is sufficient quantity for dermatological preparations for the management of dry skin condition. A total FAA content of $161.09 \mathrm{mg} / \mathrm{g}$ was reported by Kim et al (2009) after HPLC analysis on this type of mushroom originated from Korea and this was lower than the value obtained in the present study. The literature also reveals that there is a significant difference in the total FAA content of previously tested mushrooms (Sun et al. 2017) and this could be due to the difference in the harvesting time, growth condition, geographical origin in addition to the differences in extraction, derivatization, or quantification methods.

Being protein-rich substances, legume plants are expected to contain high amount of amino acids. Among the legume seeds included in the present study, dekoko (Pisum sativum var. abyssinicum (A. Braun) Berger), which obtains a premium price in local markets, contained relatively high amount of total FAAs followed by flaxseed (Linum usitatissimum L.), common bean (Phaseolus vulgaris L.), sunflower seeds (Helianthus annuus L.), soybean (Glycine max [L.] Merr.) (130.91-214.39 mg/g) (Table 1). The other legume seeds investigated were peanuts (Arachis hypogaea L.), fenugreek (Trigonella foenum-graecum L.) and sesame seed (Sesamum indicum L.) with a total FAA content of 73.62, 57.37 and $44.31 \mathrm{mg} / \mathrm{g}$, respectively. The dominant FAAs in

$\operatorname{Conc}\left(\frac{\mathrm{nmol}}{\mathrm{mg}}\right)=\frac{(\text { Peak area of analyte/Peak area of norvaline }) \times \text { nmol of norvaline in the extraction solvent }}{(\text { Slope of analyte/Slope of norvaline }) \times \text { Sample weight }(\mathrm{mg})}$

\section{Results and discussion}

The FAA contents of the different plant and mushroom species included in the present study are shown in Table 1. Evidently, the concentrations are significantly different and the total FAAs found in the water extracts of the different species tested ranged from $0.86 \mathrm{mg} / \mathrm{g}$ (peal of mango, Mangifera indica L.) to $400.01 \mathrm{mg} / \mathrm{g}$ (oyster mushroom, Pleurotus ostreatus (Jacq. ex Fr.) P. Kumm.) as calculated on dry basis. All the tested 27 FAAs were found in most of the samples most of these plants were Arg, Asp, Glu, Asn, Gln, and Leu. Previous studies on some of these plants, namely flaxseeds (Panaite et al. 2017), common bean (Fukuji et al. 2019; Saboori-Robat et al. 2019), and sunflower seeds (Robinson 1975) also indicated that the stated FAAs are the dominant ones. However, the concentrations obtained were different may be due the difference in testing methodology and source of the materials. It is also mentioned in the literature that soybean seeds are able to store nitrogen mostly in the form of either proteins or FAAs (Takahashi et al. 2003). 


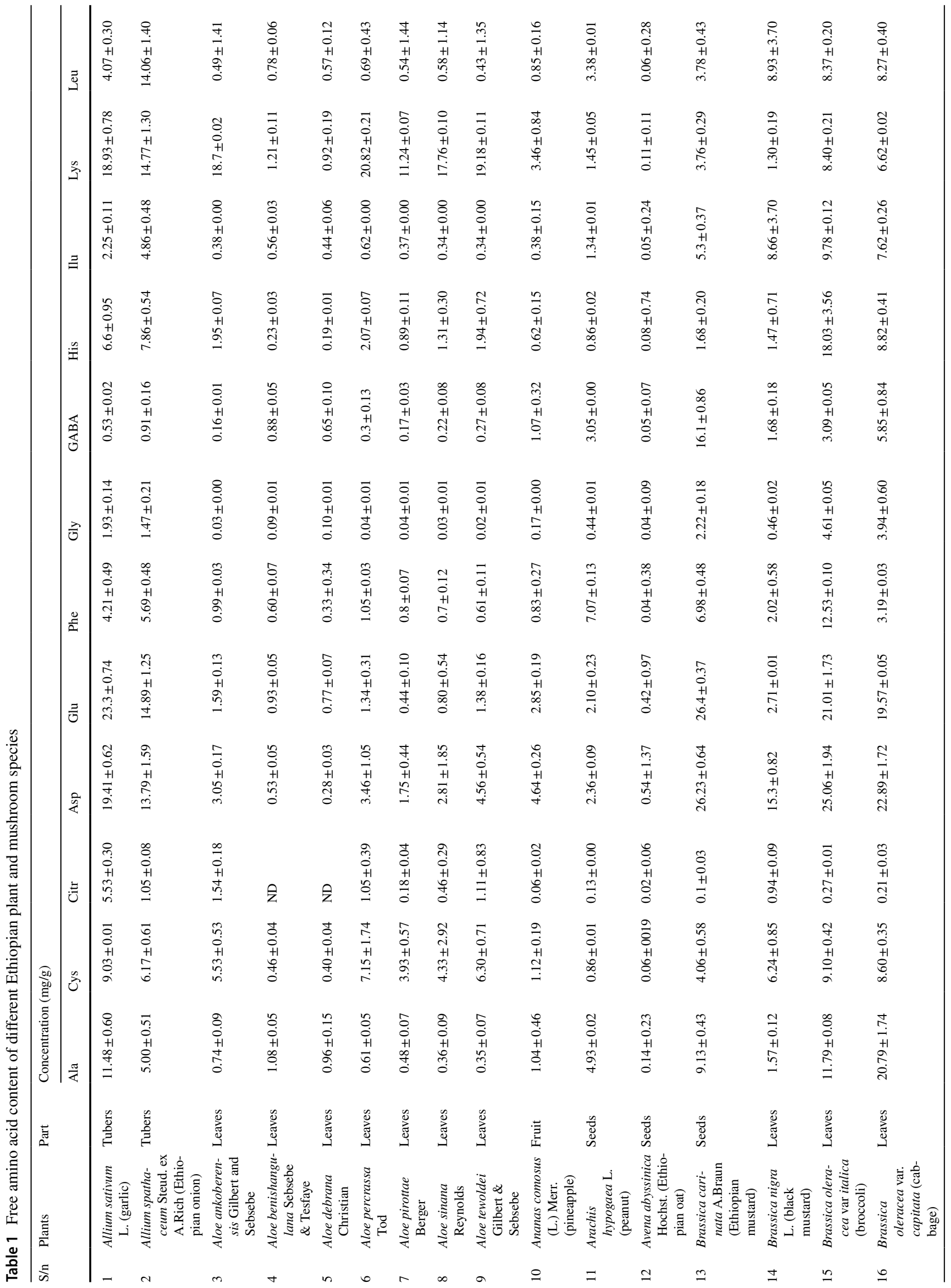




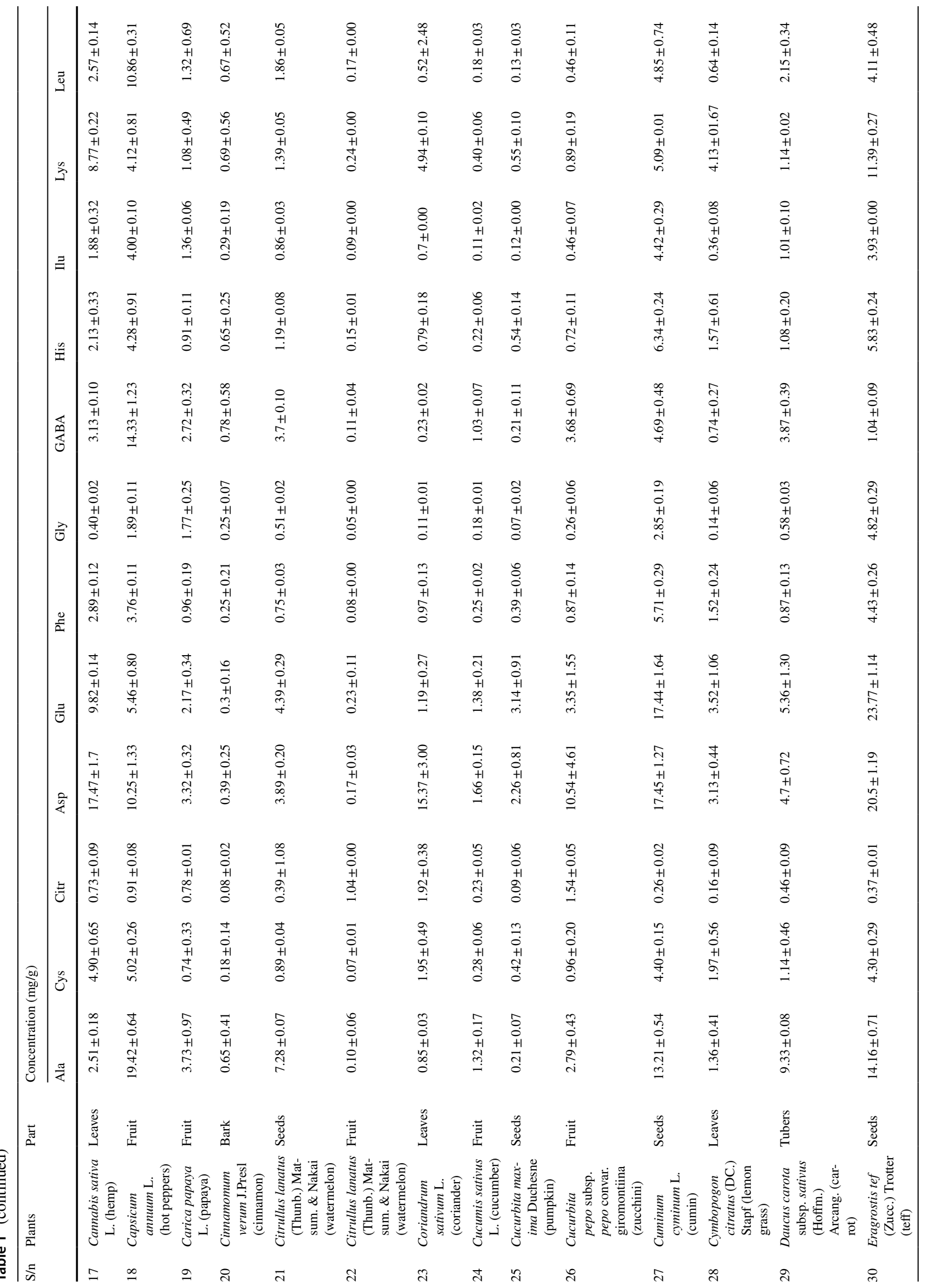




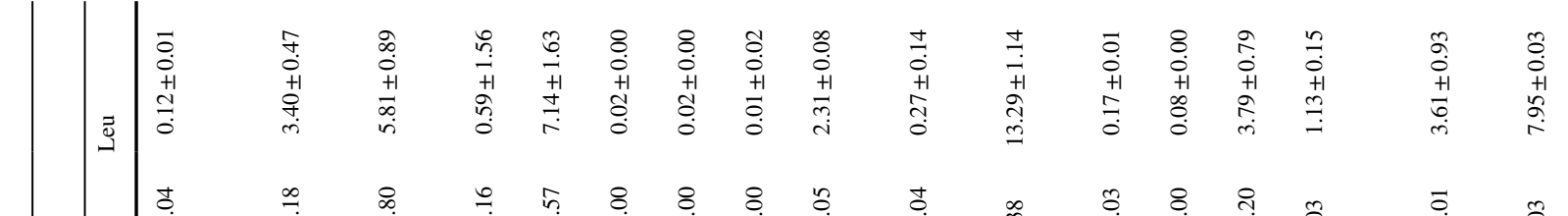

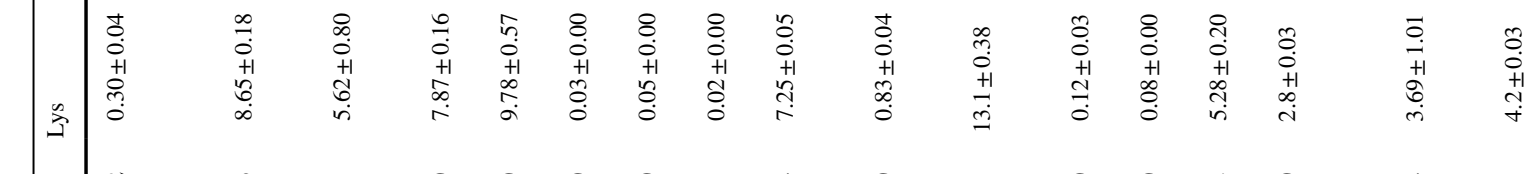

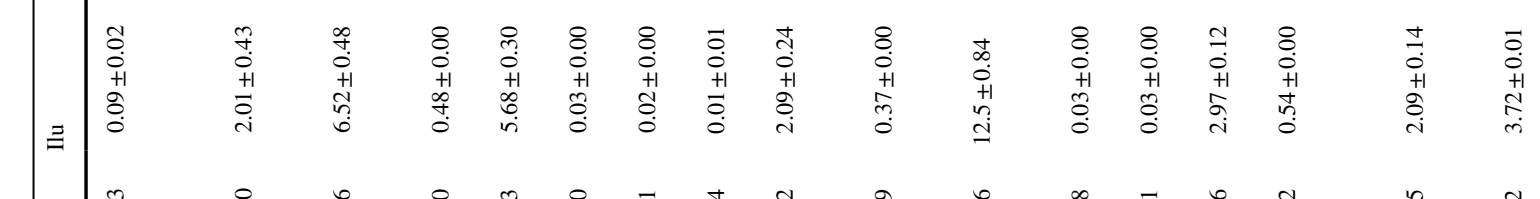

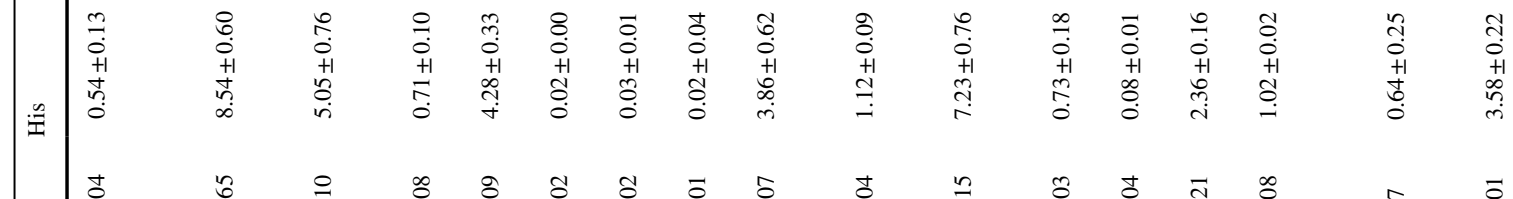

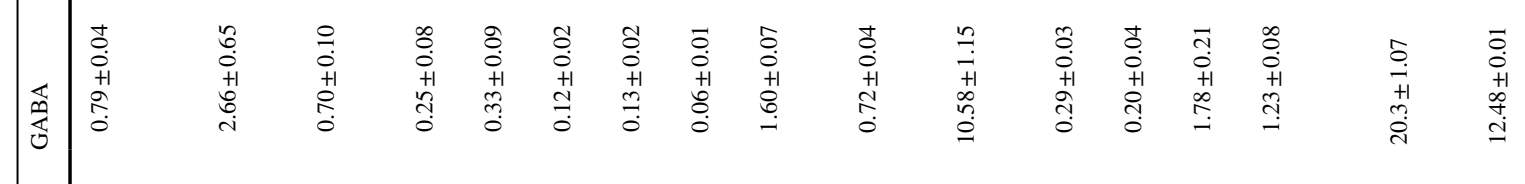

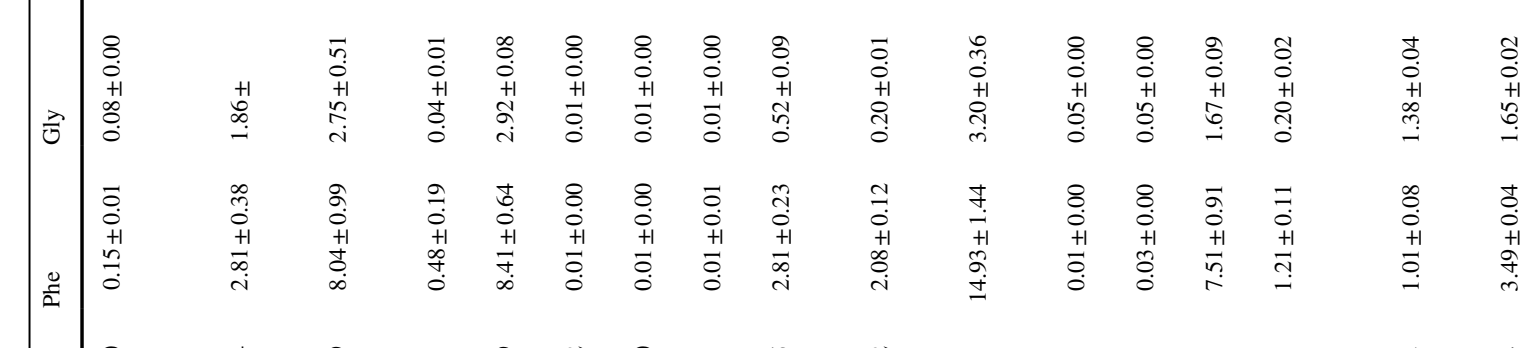

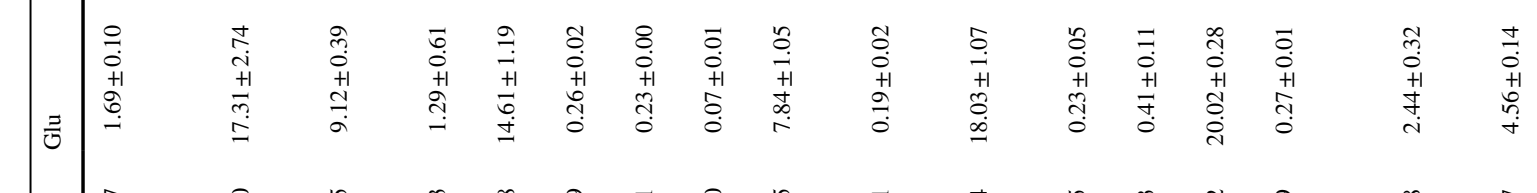

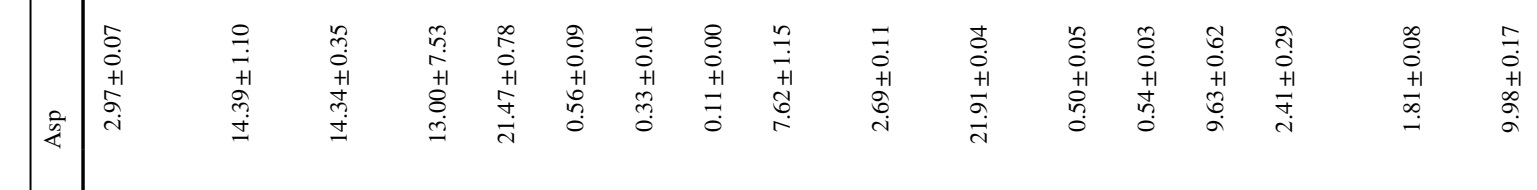

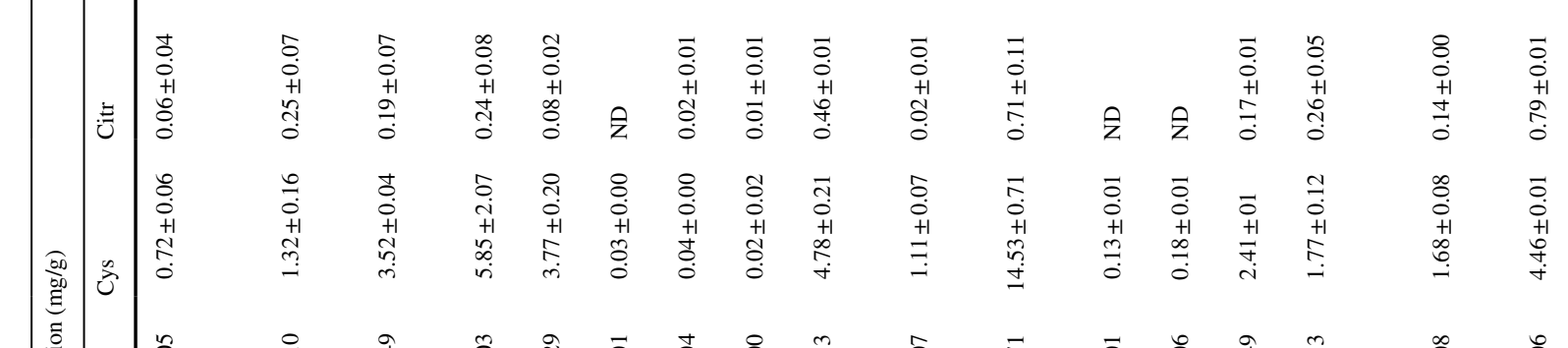

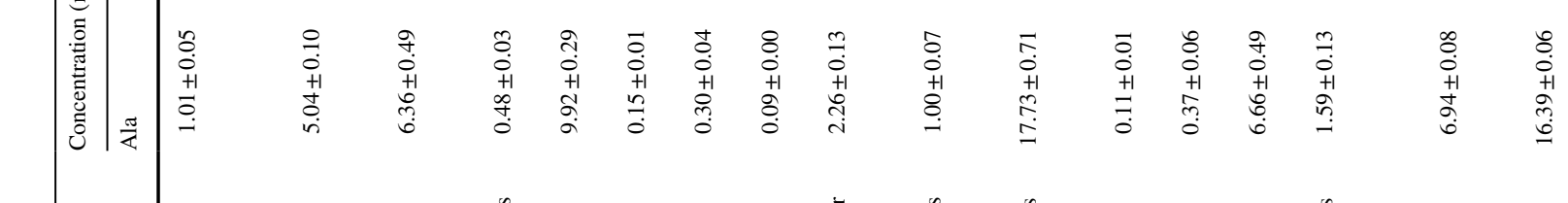

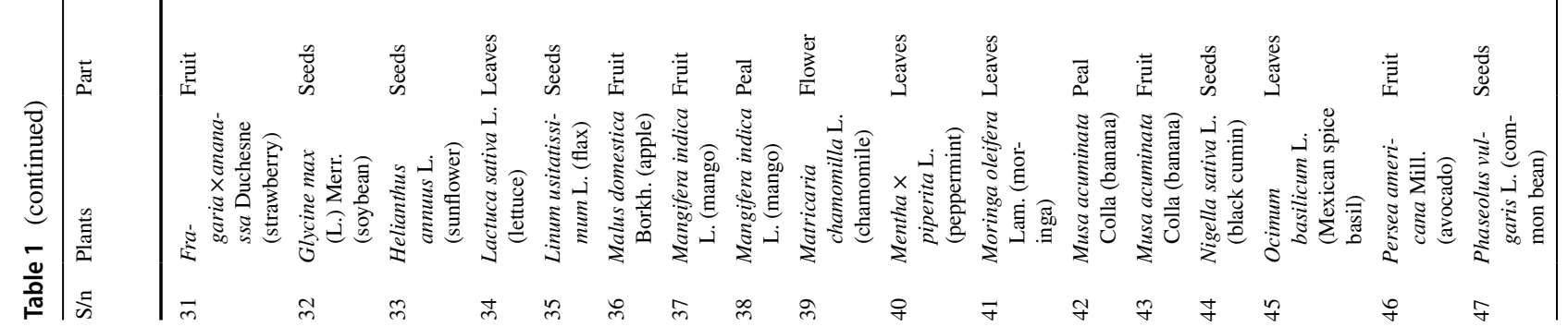




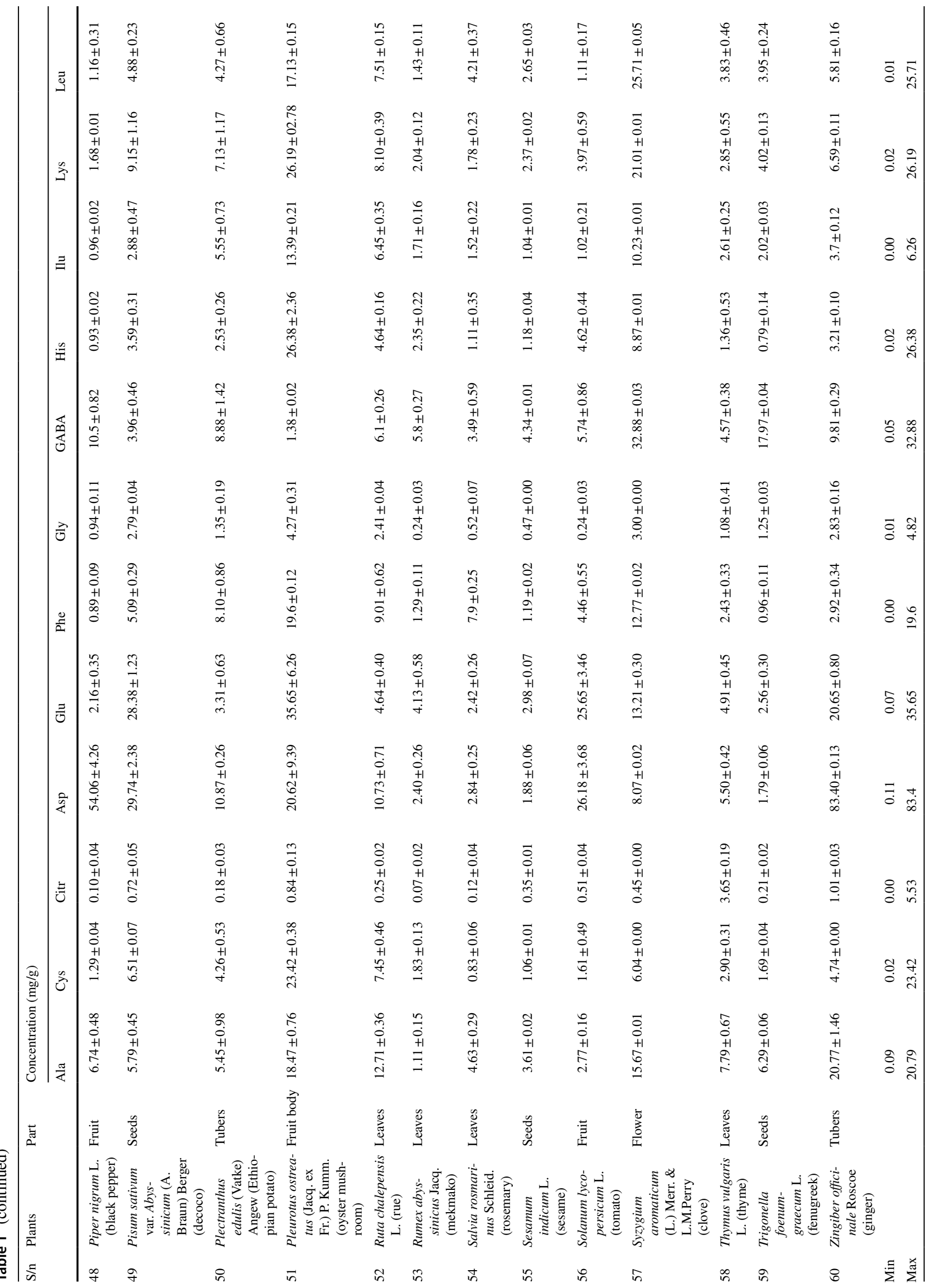




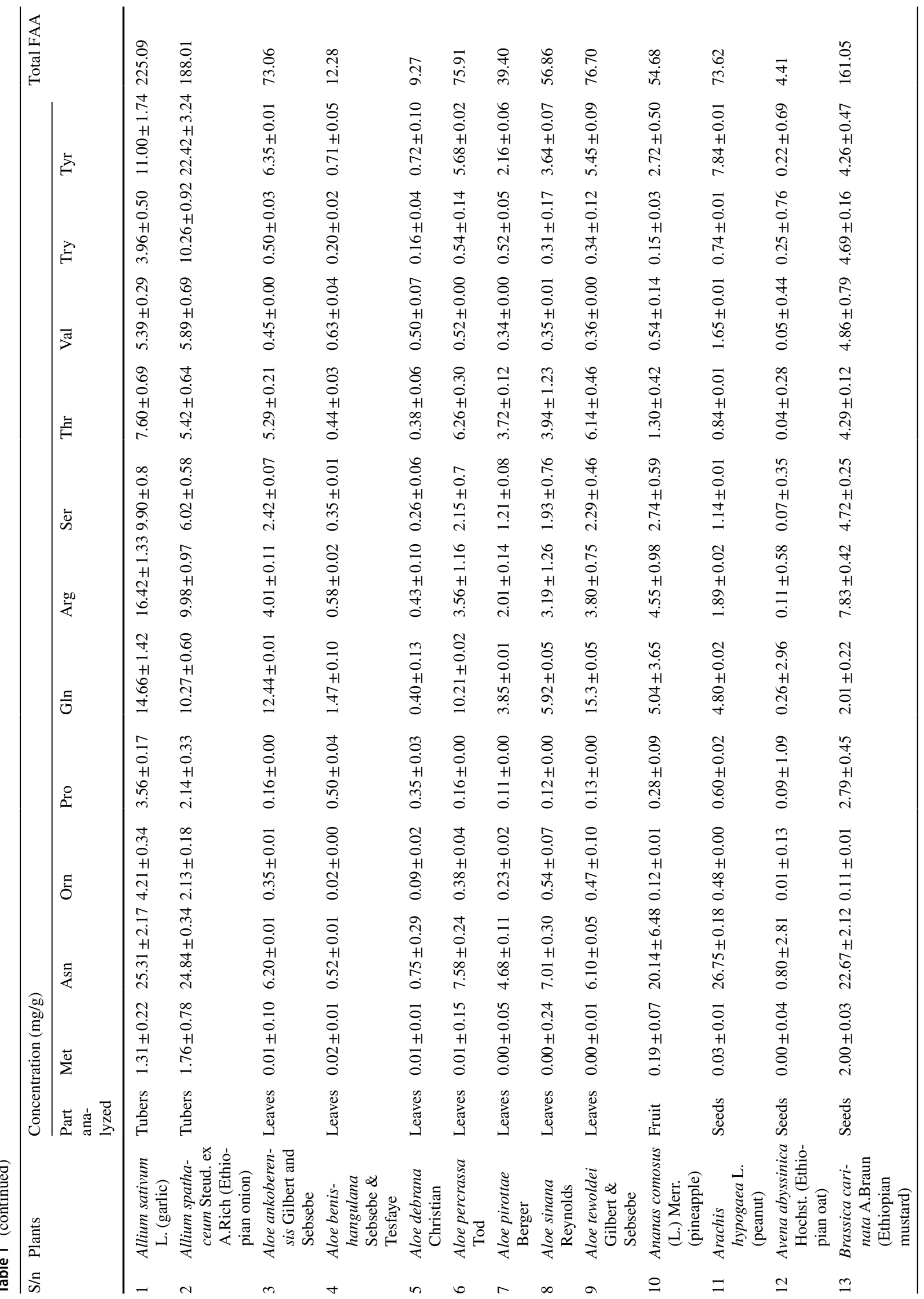




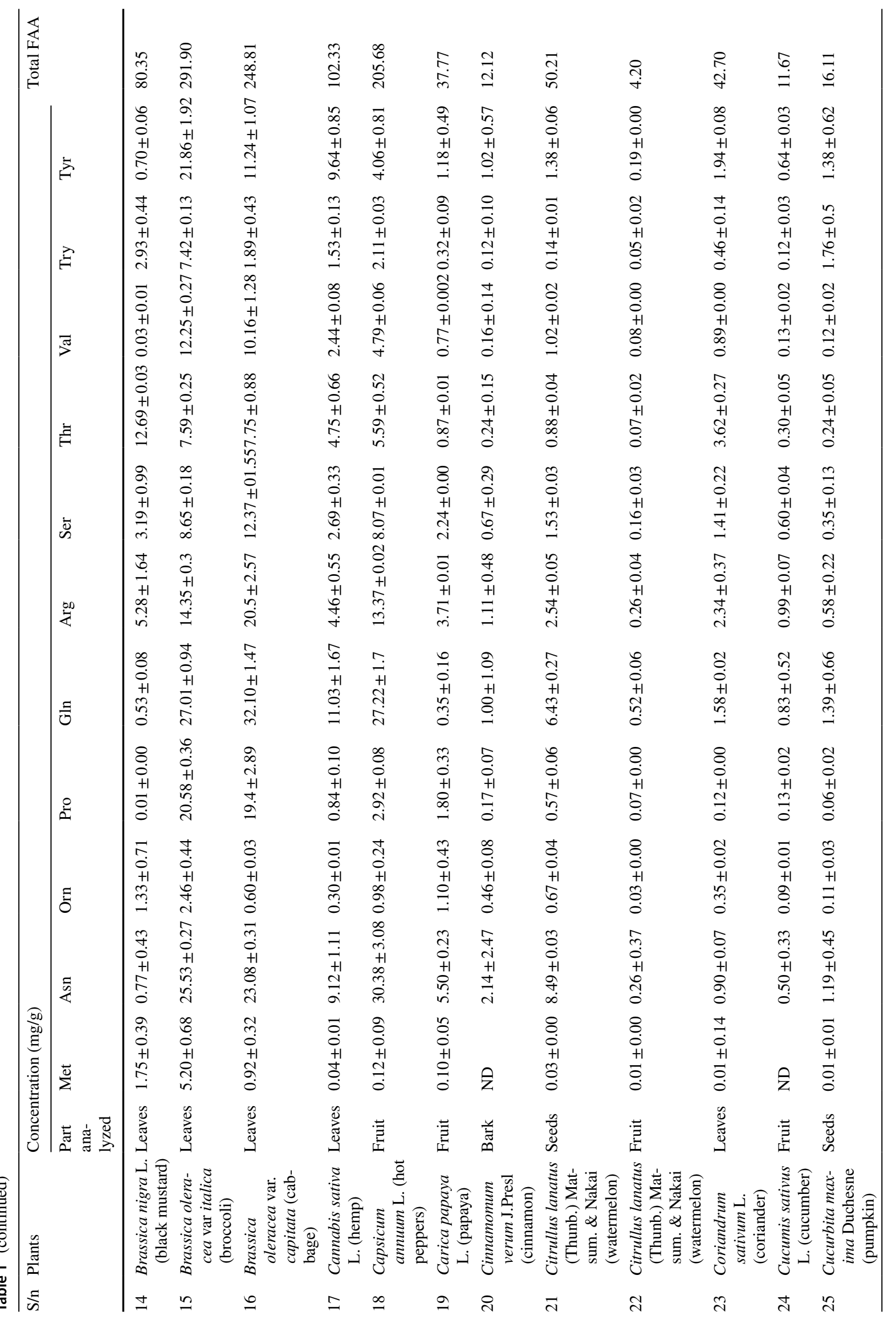




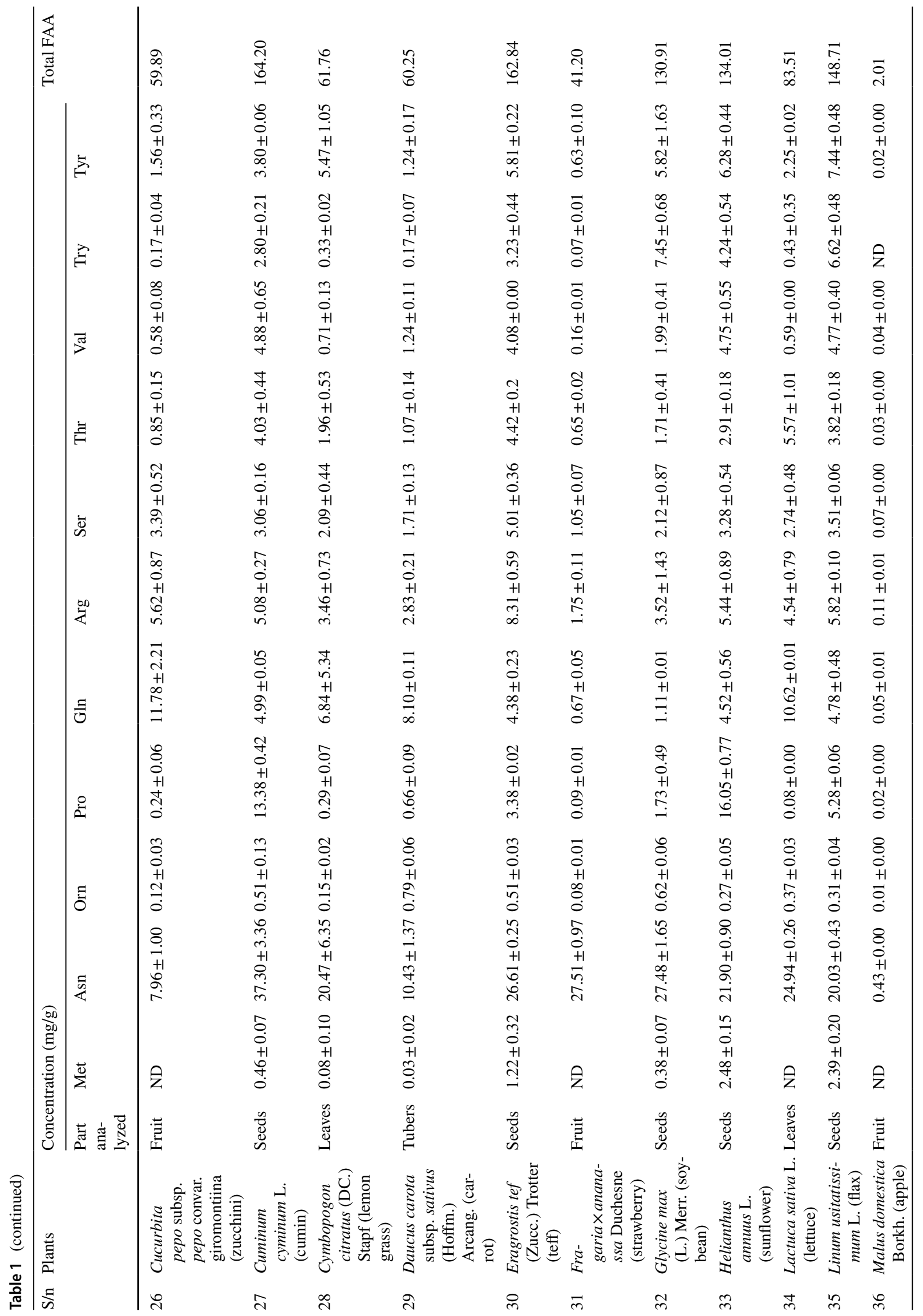




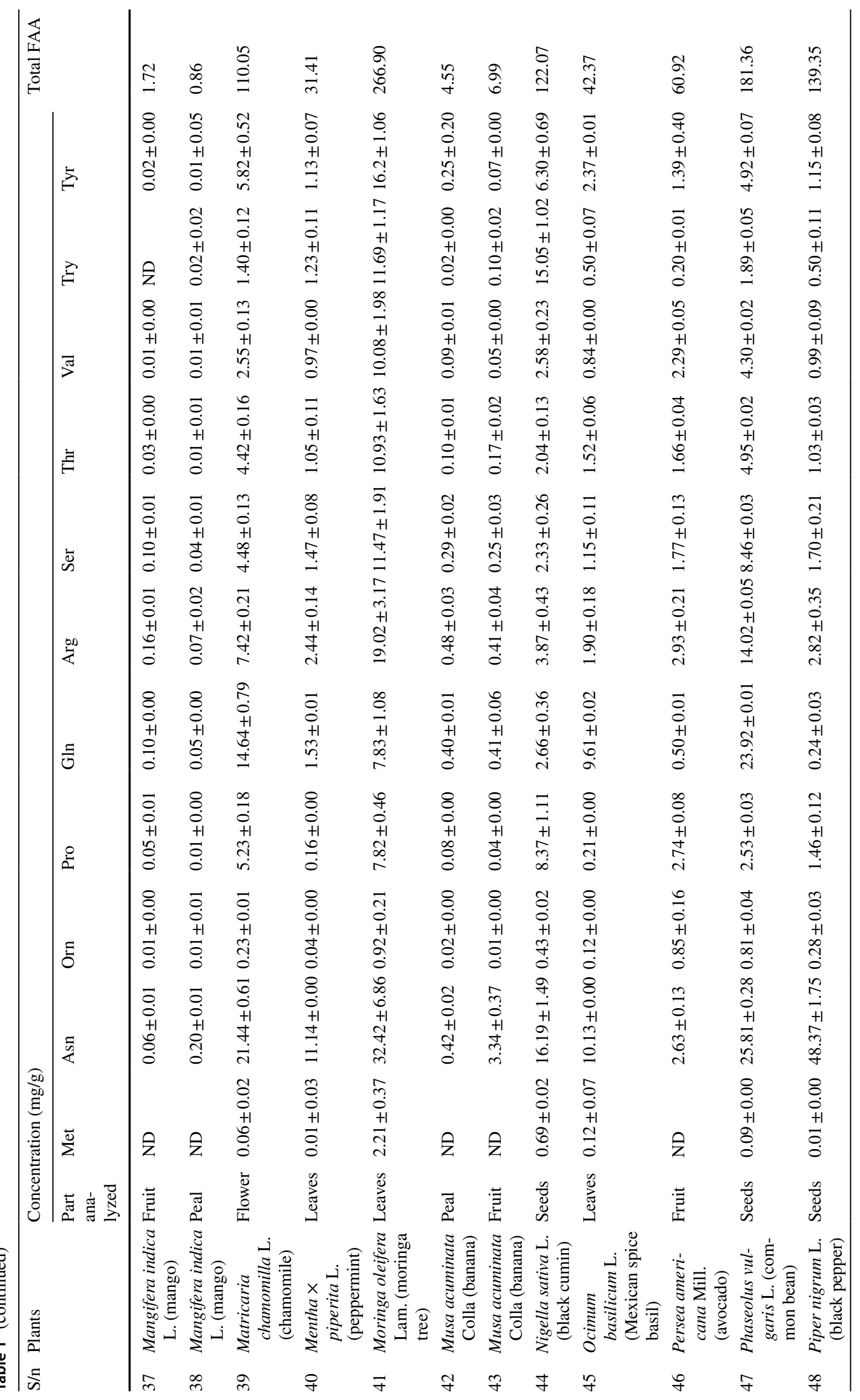




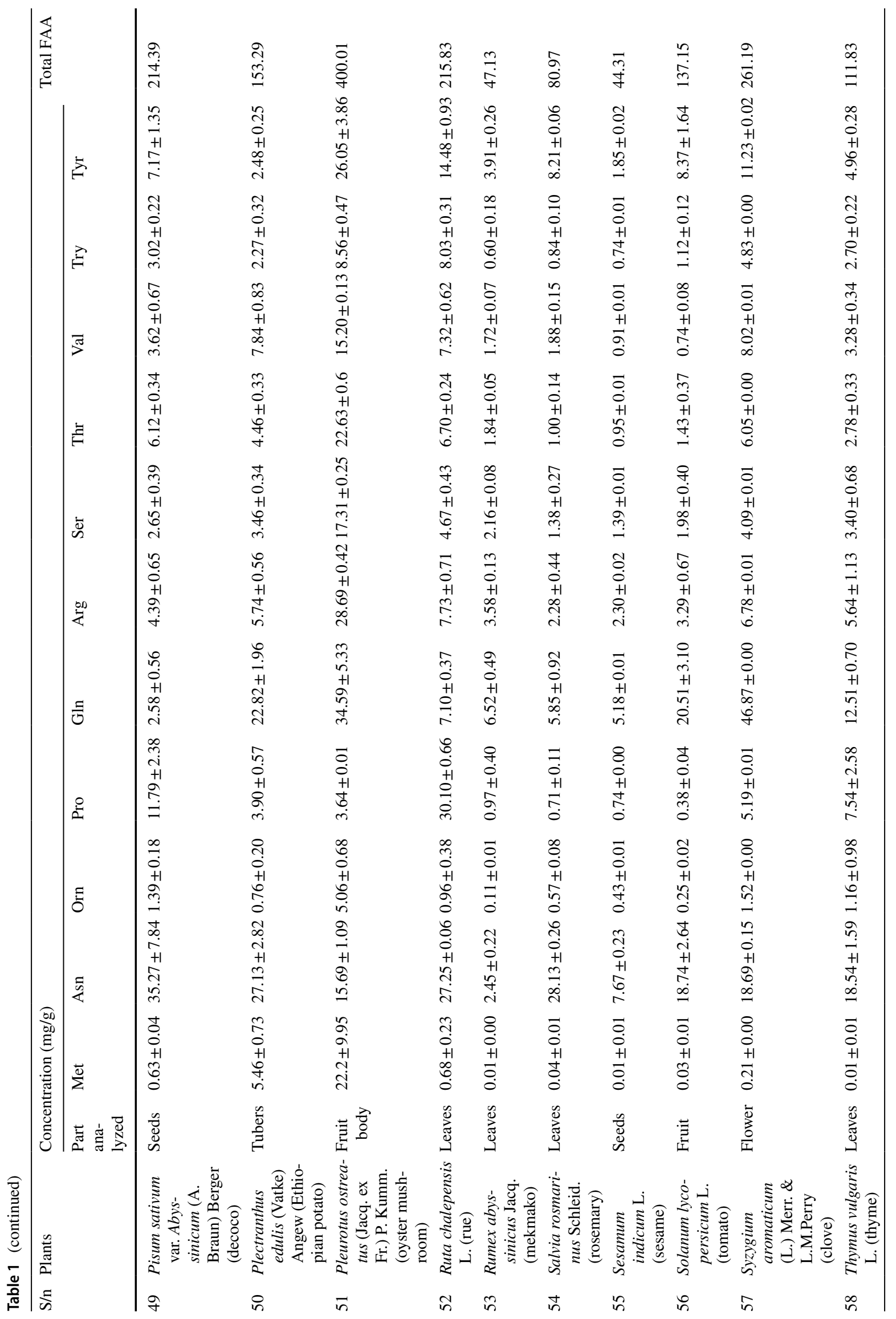




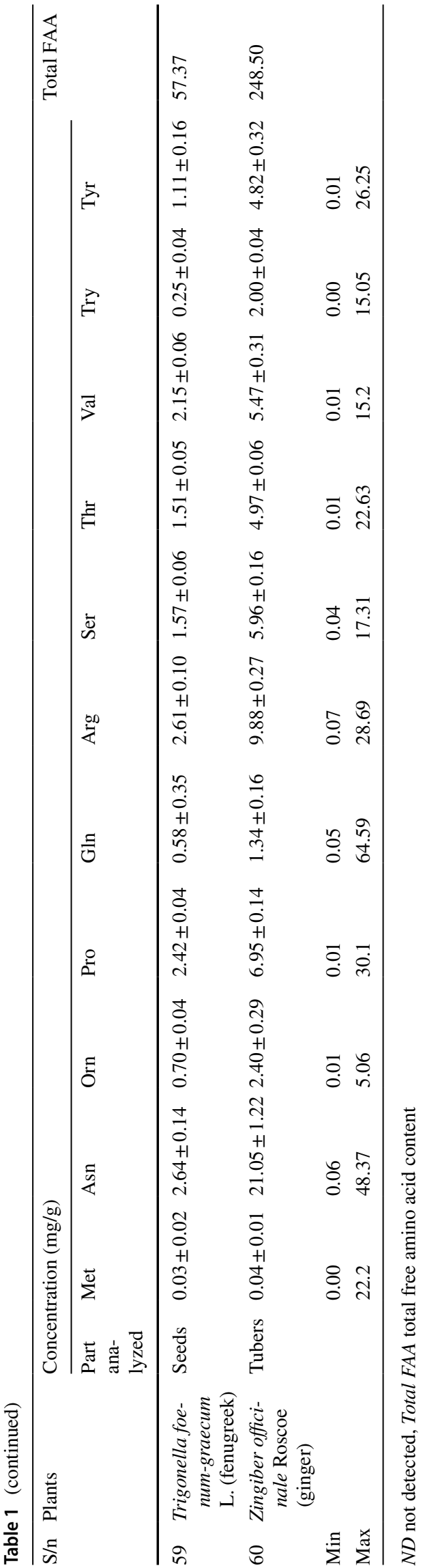

Seeds of Ethiopian oat (Avena abyssinica Hochst.) and teff (Eragrostis tef (Zuccagni) Trotter) were selected and investigated from the cereal products. Ethiopian oat had very low total FAA concentration $(4.41 \mathrm{mg} / \mathrm{g})$ while teff had a total FAA content of $162.84 \mathrm{mg} / \mathrm{g}$. The dominant FAAs in teff seeds were Glu, Asp, Asn, Ala, and Lys $(11.39-26.61 \mathrm{mg} / \mathrm{g})$.

The edible parts of 14 vegetables were included in the present study and the total FAA content was highest in broccoli (Brassica oleracea var italica Plenck) followed by garlic (Allium sativum L.), Ethiopian onion (Allium spathaceum Steud. ex A.Rich), cabbage (Brassica oleracea var. capitata (L.) Metzg.), Ethiopian mustard (Brassica carinata), black mustard (Brassica nigra L.), Ethiopian potato (Plectranthus edulis (Vatke) Agnew), tomato (Solanum lycopersicum L.), lettuce (Lactuca sativa L.) and carrot (Daucus carota subsp. sativus (Hoffm.) Schübl. \& G. Martens) in decreasing order (60.25-291.90 mg/g on dry basis) (Table 1). Among the vegetables, relatively low amount of total FAA was obtained in cucumber (Cucumis sativus L.), pumpkin (Cucurbita maxima Duchesne), coriander (Coriandrum Sativum) and zucchini (Cucurbita pepo subsp. pepo convar. Giromontiina) $(11.67-59.89 \mathrm{mg} / \mathrm{g})$. Even though most of the FAAs were greater than $7.00 \mathrm{mg} / \mathrm{g}$, the dominant FAAs found in broccoli and cabbage were Arg, Asp, and Glu. In a study by Gomes and Rosa (2001), 17 FAAs were detected in different broccoli cultivars and the dominant amino acids were Gln and Glu. A study by Oliveira (2008), reported the total FAA content ranged from 3.30 to $14.40 \mathrm{mg} / \mathrm{g}$ after HPLC/ UV analysis, indicated that the dominant FAAs in cabbage were Arg, Pro, and Thr. Garlic and Ethiopian onion were dominated by FAAs such as Arg, Glu, Lys, Asn, Gln, Asp, Leu, Gln, Try, and Ala (Table 1). Another study by Lee and Harnly (2005) indicated that 18 FAAs were present in garlic and the dominant FAAs reported were Gln, Asn, Glu, Lys, Pro, and Ser. Ethiopian potato and tomato were also dominated with free form Gln, Asn, and Asp. Investigation on other potato species also indicated that FAAs of high concentration were obtained after extracting with hot water (Furudate and Meguro 2001). Even though it is mentioned in the literature that Cit occurs most abundantly in Cucurbitaceous plants (Joshi and Fernie 2017), zucchini and cucumber had low concentration of this compound (Table 1).

Among the fruits and fruit peals included in this study, avocado (Persea americana Mill.) had the highest total FAA content $(60.92 \mathrm{mg} / \mathrm{g})$, followed by pineapple (Ananas comosus (L.) Merr), watermelon (Citrullus lanatus (Thunb.) Matsum. \& Nakai), papaya (Carica papaya L.), strawberry (Fragaria $\times$ ananassa DUCHESNE), banana (Musa acuminata Colla), and mango (Mangifera indica $\mathrm{L}$.) with a total FAA contents in the range of $1.72-54.68 \mathrm{mg} / \mathrm{g}$. The peals of banana and mango were also tested but their FAA contents were very low (total FAA concentrations of 4.55 and 
$0.86 \mathrm{mg} / \mathrm{g}$, respectively). The dominant FAAs in most of the fruit samples were Asn, GABA, Asp, Glu, Gln, Ala, Ser, and Lys. A study by Zeng et al (2015) on different fruit juices, FAAs such as Asp, Glu, Asn, Ser, and Gln were the dominant ones in most samples which shows almost the same pattern as the present study.

Spices commonly used in Ethiopian traditional dishes have also promising amount of FAAs (Table 1). Ginger (Zingiber officinale Roscoe), a plant with diverse biological activities (Zhao et al. 2011), had total FAA content of $248.50 \mathrm{mg} / \mathrm{g}$. The dominant FAAs were Asp, Asn, Ala, Glu and Arg (9.88-83.40 mg/g). Met was found at a very low concentration $(0.04 \mathrm{mg} / \mathrm{g})$. Ogbuewu et al. (2014) who tested 17 amino acids reported a total amino acid content of $256.10 \mathrm{mg} / \mathrm{g}$, also indicated Arg as the most dominant amino acid and Met at relatively lower concentration compared to the other FAAs. Cumin (Cuminum cyminum L.) and black cumin (Nigella sativa L.), which are active reservoirs of numerous bioactive compounds with various therapeutic applications, had total FAA concentrations of 164.20 and $122.07 \mathrm{mg} / \mathrm{g}$, respectively. FAAs such as Arg, Asn, Asp, Glu, Pro, and Ala were the most abundant FAAs in both of them. Reports on cumin also indicate that the seeds of this plant are rich in FAAs (Badr and Georgiev 1990; Toghrol and Daneshpejouh 1974). Moreover, a study by Yimer et al. (2019) also revealed that Glu, Arg, and Asp are the major amino acids found in black cumin which is consistent with the present study. Hot peppers (Capsicum anпиит L.) and black pepper (Piper nigrum L.) contribute a major share in the Ethiopian spice scenario. The total FAA contents of these plants were 205.68 and $139.35 \mathrm{mg} / \mathrm{g}$, respectively. Free forms of Asn, Ala, GABA, and Asp were found at high concentrations $(6.94-54.06 \mathrm{mg} / \mathrm{g})$ in both plants. A study on hot pepper seeds grown in China, 18 amino acids were detected and the main amino acids were Glu and Asp (both of which had concentrations of above $20.00 \mathrm{mg} / \mathrm{g}$ ) (Zou et al. 2015). The remaining spices, namely, rosemary (Salvia rosmarinus SCHLEID.), lemon grass (Cymbopogon citratus (DC.) Stapf) and cinnamon (Cinnamomum verum J. Presl) had a total FAA contents of less than $81.00 \mathrm{mg} / \mathrm{g}$.

The leaves of some herbs, namely, chamomile (Matricaria chamomilla $\mathrm{L}$.), peppermint (Mentha $\times$ piperita $\mathrm{L}$.), Mexican spice basil (Ocimum basilicum L.), rue (Ruta chalepensis L.), and thyme (Thymus vulgaris L. were also included in the present study. Highest total FAAs were found in rue, chamomile and thyme (110.05-215.83 mg/g) (Table 1). Chamomile, which is often referred to as the "star among medicinal species", is a well-known medicinal plant species from the Asteraceae family (Singh et al. 2011). The present study indicated that this plant is dominated with FAAs such as Asn, Gln, Asp, Glu, Lys, Arg, and Pro. A study by Ma et al. (2015), 15 FAAs were detected and analyzed by HPLC and the dominant FAAs reported were Pro,
Ala, Ser, Glu, Asp, and Arg. Mekmeko (Rumex abyssinicus Jacq.), another perennial herb, had a total FAA content of $47.10 \mathrm{mg} / \mathrm{g}$.

Among the seven indigenous aloe species included in this study, relatively high total FAA content was obtained in Aloe percrassa Tod., A. tewoldei M.G. Gilbert \& Sebsebe and A. ankoberensis M.G. Gilbert \& Sebsebe (73.06-76.70 mg/g). The dominant FAAs were slightly different in the different species of aloe. In previous study by Kim et al. (2013), a total of 24, 23 and 17 amino acids were detected in three species of aloe, namely, A. vera (L.) Burm.f., A. saponaria (Aiton) Haw., and A. arborescens Mill., respectively, indicating that different species can have different composition.

The leaves of other plants grown in Ethiopia were also included. Moringa (Moringa oleifera Lam.), a highly valued plant with exceptional nutritional value and array of health benefits, is widely grown in many tropical and subtropical countries. In the present study, the total FAA content of the leaf part of moringa tree was $449.71 \mathrm{mg} / \mathrm{g}$. The dominant amino acids were Asg, Ala, Asp, Glu, Ser, and Leu. Hemp (Cannabis sativa L.) and clove (Syzygium aromaticum (L.) Merr. \& L.M. Perry)) had total FAA concentration of 195.01 and $261.29 \mathrm{mg} / \mathrm{g}$, respectively. FAAs such as Asp, Gln, Asn, Glu, Lys, and Tyr were the dominant ones in both. Previous studies on protein isolates of hemp also revealed that the plant had high amount of amino acids (Tang et al. 2006).

In general, the present study revealed that FAAs for cosmeceutical applications can be obtained from several nature-based resources. As reported by Hussain et al (2019), the concentration of each FAA in the stratum corneum of healthy human skin is less than $10.00 \mathrm{nmol} / \mathrm{mg}$ indicating that only very low amount of these bioactive molecules are required in formulations pertaining to replacement therapies for the treatment of dry skin conditions. As can be seen from the results in Table 1, natural resources including but not limited to oyster mushroom, broccoli, garlic, Ethiopian onion, ginger, cabbage, cumin, and decoco contain a significant amount of most of the FAAs. Among the tested FAAs, free Asp, Asn, Glu, Arg, Gln, GABA, His, Ala, Ser, Thr, Tyr, Try, Leu, Ile, Val, Pro, Phe, Gly, Pro, and Lys were dominantly found in these and the other plants. Even though the remaining FAAs, namely, Tau, Cit, Orn, oxyproline, $O$-acetylserine, and methionine oxide were found at low concentrations in most of the tested samples, they were found in sufficient quantity in some of the plants and in the mushroom. For example, oyster mushroom can be considered as source of Met, Cys and Orn. Moreover, sufficient amount of Tau and $O$-acetylserine were obtained in black mustard; and reasonable content of Cit was obtained in garlic. Hence, a crude extract of some of the stated plants have all the required FAAs and use of such resources for cosmeceutical applications has a great advantage over other 
sources (synthetic, enzymatic, and fermentation) in terms of economic benefits besides other nature-related advantages.

The natural products that had the highest amount of FAAs as per the current study have also been used in many cosmeceutical preparations. For example "Birch Water Purifying Essence", "Larecea ${ }^{\mathrm{TM}}$ Extract". and "Onion Juice Cream" are some examples of commercially available cosmeceutical preparations which contain extracts from mushroom, broccoli, and onion as their main components. Despite the few commercial moisturizers that contain nature-based extracts, to our knowledge, much research work has not been done on topical formulations loaded with plant or mushroom-based FAAs. The current study gives a clear insight to the natural products with high amounts of FAAs and will help to fill the research gap in topical preparations loaded with plant or mushroom-based FAA.

\section{Conclusion}

In the present study, the FAA content of selected Ethiopian plant and mushroom species were investigated. The results revealed that significant amount of all the FAAs found in NMF were obtained in most of the investigated materials. Among the tested species, those with very short harvesting period (such as oyster mushroom, broccoli, garlic, ginger, cabbage, and pepper) can be considered as sources of these bioactive molecules. Simple extraction of FAA from natural resources for cosmeceutical preparation can be considered as alternative method to synthetic, enzymatic and fermentation methods, especially in low-income countries. In addition to its therapeutic advantages, use of such nature-based compounds for cosmeceutical purpose in biodiversity-rich countries like Ethiopia could have economic benefit. It also helps in fostering modern natural remedial approaches and fulfills customer satisfactions.

Supplementary Information The online version contains supplementary material available at https://doi.org/10.1007/s00726-021-03008-5.

Acknowledgements The authors would like to thank Regional Bioequivalence Center and Addis Ababa University, Ethiopia for sponsoring the $\mathrm{PhD}$ study of $\mathrm{BN}$, Martin Luther University and Leibniz Institute of Plant Biochemistry, Germany for providing access to their laboratory facilities.

Funding Open Access funding enabled and organized by Projekt DEAL. This study is a part of the project Phytosustain funded by German Academic Exchange Service (DAAD) (Grant Number 57369155) and Federal Ministry of Education and Research (BMBF) (Grant Number 01DG17008B), Germany.

Data availability The original data obtained from the calibration curves (in $\mathrm{nmol} / \mathrm{mg}$ ) are attached in the electronic supplement.

\section{Declarations}

Conflict of interest The authors declare that they have no conflict of interest.

Research involving human participants and/or animals This research did not involve human participants or animals.

Informed consent Informed consent obtaining for this type of study is not required.

Open Access This article is licensed under a Creative Commons Attribution 4.0 International License, which permits use, sharing, adaptation, distribution and reproduction in any medium or format, as long as you give appropriate credit to the original author(s) and the source, provide a link to the Creative Commons licence, and indicate if changes were made. The images or other third party material in this article are included in the article's Creative Commons licence, unless indicated otherwise in a credit line to the material. If material is not included in the article's Creative Commons licence and your intended use is not permitted by statutory regulation or exceeds the permitted use, you will need to obtain permission directly from the copyright holder. To view a copy of this licence, visit http://creativecommons.org/licenses/by/4.0/.

\section{References}

Arezki NR, Williams AC, Cobb JA, Brown MB (2017) Design, synthesis and characterization of linear unnatural amino acids for skin moisturization. Int J Cosmet Sci 39(1):72-82

Azmir J, Zaidul ISM, Rahman MM, Sharif KM, Mohamed A, Sahena F, Jahurul MHA, Ghafoor K, Norulaini NAN, Omar AKM (2013) Techniques for extraction of bioactive compounds from plant materials: a review. J Food Eng 117(4):426-436

Badr FH, Georgiev EV (1990) Amino acid composition of cumin seed (Cuminum cyminum L.). Food Chem 38(4):273-278

Bandaranayake WM (2006) Quality control, screening, toxicity, and regulation of herbal drugs. Modern phytomedicine: turning medicinal plants into drugs. Wiley-VCH Verlag $\mathrm{GmbH} \& \mathrm{Co}$. $\mathrm{KGaA}$, pp 25-57

Berhan T, Egziabher G (2009) Diversity of the Ethiopian flora. Plant genetic resources of Ethiopia. Cambridge University Press, London, pp 75-81

Burke RC, Lee TH, Buettner-Janusch V (1966) Free amino acids and water soluble peptides in stratum corneum and skin surface film in human beings. Yale J Biol Med 38(4):355-373

Calixto JB (2019) The role of natural products in modern drug discovery. An Acad Bras Ciencias 91(3):1-7

Caspers PJ, Lucassen GW, Carter EA, Bruining HA, Puppels GJ (2001) In vivo confocal Raman microspectroscopy of the skin: noninvasive determination of molecular concentration profiles. J Invest Dermatol 116(3):434-442

Chikezie PC, Ibegbulem CO, Mbagwu FN (2015) Bioactive principles from medicinal plants. Res J Phytochem 9(3):88-115

Demain AL (2000) Microbial biotechnology. Trends Biotechnol 18(1):26-31

Fukuji AYS, Constantino LV, Zeffa DM, de Andrade FA, da Silva MB, Gonçalves LSA (2019) Amino acid concentration, total phenolic compound content and antioxidant activity of snap bean genotypes. Braz J Food Technol 22:e2018069,1-6

Furudate A, Meguro T (2001) Free amino acids in potato tubers and their extraction by boiling water. J Home Econ Japan 52(1):71-74 
Garg RP, Qian XL, Alemany LB, Moran S, Parry RJ (2008) Investigations of valanimycin biosynthesis: elucidation of the role of seryltRNA. Proc Natl Acad Sci USA 105(18):6543-6547

Gomes MH, Rosa E (2001) Free amino acid composition in primary and secondary inflorescences of 11 broccoli (Brassica oleracea var italica) cultivars and its variation between growing seasons. J Sci Food Agric 81(3):295-299

Hussain H, Ziegler J, Hause G, Wohlrab J, Neubert RHH (2019) Quantitative analysis of free amino acids and urea derived from isolated corneocytes of healthy young, healthy aged, and diseased skin. Skin Pharmacol Physiol 32(2):94-100

Ikeda M (2003) Amino acid production processes. Adv Biochem Eng Biotechnol 79:1-35

Ji S, Fattahi A, Raffel N, Hoffmann I, Beckmann MW, Dittrich R, Schrauder M (2017) Antioxidant effect of aqueous extract of four plants with therapeutic potential on gynecological diseases; Semen persicae, Leonurus cardiaca, Hedyotis diffusa, and Curcuma zedoaria. Eur J Med Res 22(50):1-8

Jokura Y, Ishikawa S, Tokuda H, Imokawa G (1995) Molecular analysis of elastic properties of the stratum corneum by solid-state 13C-nuclear magnetic resonance spectroscopy. J Invest Dermatol 104(5):806-812

Jose N, Janardhanan KK (2000) Antioxidant and antitumour activity of Pleurotus florida. Curr Sci 79(7):941-943

Joshi V, Fernie AR (2017) Citrulline metabolism in plants. Amino Acids 49(9):1543-1559

Khan MA, Tania M (2012) Nutritional and medicinal importance of Pleurotus mushrooms: an overview. Food Rev Int 28(3):313-329

Kim MY, Chung IM, Lee SJ, Ahn JK, Kim EH, Kim MJ, Kim SL et al (2009) Comparison of free amino acid, carbohydrates concentrations in Korean edible and medicinal mushrooms. Food Chem 113:386-393

Kim YK, Suh SY, Uddin MR, Kim YB, Kim HH, Lee SW, Park SU (2013) Variation in amino acid content among three Aloe species. Asian J Chem 25(11):6346-6348

Kwan P, Sills GJ, Brodie MJ (2012) Understanding the role of NMF in skin hydration. Pract Dermatol July(1):21-34

Lee J, Harnly JM (2005) Free amino acid and cysteine sulfoxide composition of 11 garlic (Allium sativum L.) cultivars by gas chromatography with flame ionization and mass selective detection. $\mathrm{J}$ Agric Food Chem 53(23):9100-9104

Lee DY, Kim EH (2019) Therapeutic effects of amino acids in liver diseases: current studies and future perspectives. J Cancer Prev 24(2):72-78

Leuchtenberger W, Huthmacher K, Drauz K (2005) Biotechnological production of amino acids and derivatives: current status and prospects. Appl Microbiol Biotechnol 69(1):1-8

Louard RJ, Barrett EJ, Gelfand RA (1990) Effect of infused branchedchain amino acids on muscle and whole-body amino acid metabolism in man. Clin Sci 79(5):457-466

Ma X, Zhao D, Li X, Meng L (2015) Chromatographic method for determination of the free amino acid content of chamomile flowers. Pharmacogn Mag 11(41):176-179

Mau JL, Lin YP, Chen PT, Wu YH, Peng JT (1998) Flavor compounds in king oyster mushrooms Pleurotus eryngii. J Agric Food Chem 46(11):4587-4591

Meletis CD, Barker JE (2005) Therapeutic uses of amino acids. Altern Complement Ther 11(1):24-28

Mueller U, Huebner S (2003) Economic aspects of amino acids production. Adv Biochem Eng Biotechnol 79:137-170

Nagalingam A (2017) Drug delivery aspects of herbal medicines. Japanese Kampo medicines for the treatment of common diseases: focus on inflammation. Elsevier, pp 143-164

Naylor CD, O'Rourke K, Detsky AS, Baker JP (1989) Parenteral nutrition with branched-chain amino acids in hepatic encephalopathy. A meta-analysis. Gastroenterology 97(4):1033-1042
Newman DJ, Cragg GM (2012) Natural products as sources of new drugs over the 30 years from 1981 to 2010. J Nat Prod 75(3):311-335

Newsholme EA, Crabtree B, Ardawi MS (1985) Glutamine metabolism in lymphocytes: its biochemical, physiological and clinical importance. Q J Exp Physiol 70(4):473-489

Oliveira AP, Pereira DM, Andrade PB, Valentão P, Sousa C, Pereira JA, Bento A, Rodrigues MÂ, Seabra RM, Silva BM (2008) Free amino acids of tronchuda cabbage (Brassica oleracea L. Var. costata DC): Influence of leaf position (internal or external) and collection time. J Agric Food Chem 56(13):5216-5221

Panaite T, Ropota M, Turcu R, Olteanu M, Corbu AR, Nour V (2017) Flaxseeds: nutritional potential and bioactive compounds. Bull Univ Agric Sci Vet Med Cluj-Napoca Food Sci Technol 74(2):65

Park JH, Lee SY (2008) Towards systems metabolic engineering of microorganisms for amino acid production. Curr Opin Biotechnol 19(5):454-460

Phillipson JD (2001) Phytochemistry and medicinal plants. Phytochemistry 56(3):237-243

Robinson RG (1975) Amino acid and elemental composition of sunflower and pumpkin seeds 1. Agron J 67(4):541-544

Ruhsam M, Hollingsworth PM (2018) Authentication of Eleutherococcus and Rhodiola herbal supplement products in the United Kingdom. J Pharm Biomed Anal 149:403-409

Saboori-Robat E, Joshi J, Pajak A, Renaud J, Marsolais F, SabooriRobat E, Sol M, Maccelli C, Joshi J, Marsolais F, Joshi J, Mohsenpour M (2019) Common bean (Phaseolus vulgaris L.) accumulates most $S$-Methylcysteine as its glutamyl dipeptide. Plants $8(5): 126$

Sandberg F, Corrigan D (2001) Natural remedies. Their origins and uses. Taylor and Francis, New York

Segneanu A, Velciov SM, Olariu S, Cziple F, Damian D, Grozescu I (2017) Bioactive molecules profile from natural compounds. Amino acid-new insights and roles in plant and animal. IntechOpen, pp 209-228

Sharma N, Singh P, Gupta SK (2019) A review on role of various medicinal plants in cosmetics and cure health. Curr Res Pharm Sci 9(3):37-41

Singh O, Khanam Z, Misra N, Srivastava MK (2011) Chamomile (Matricaria chamomilla $\mathrm{L}$.): an overview. Pharmacogn Rev 5(9):82-95

Srivastava A, Srivastava P, Pandey A, Khanna VK, Pant AB (2018) Phytomedicine: a potential alternative medicine in controlling neurological disorders. New look to phytomedicine: advancements in herbal products as novel drug leads. Elsevier, pp 625-655

Stoimenova A, Ivanov K, Obreshkova D, Saso L (2013) Biotechnology in the production of pharmaceutical industry ingredients: amino acids. Biotechnol Biotechnol Equip 27(2):3620-3626

Sun L, Liu Q, Bao C, Fan J (2017) Comparison of free total amino acid compositions and their functional classifications in 13 wild edible mushrooms. Molecules 22:350

Takada S, Naito S, Sonoda J, Miyauchi Y (2012) Noninvasive in vivo measurement of natural moisturizing factor content in stratum corneum of human skin by attenuated total reflection infrared spectroscopy. Appl Spectrosc 66(1):26-32

Takahashi M, Uematsu Y, Kashiwaba K, Yagasaki K, Hajika M, Matsunaga R, Komatsu K, Ishimoto M (2003) Accumulation of high levels of free amino acids in soybean seeds through integration of mutations conferring seed protein deficiency. Planta 217(4):577-586

Takaoka M, Okumura S, Seki T, Ohtani M (2019) Effect of aminoacid intake on physical conditions and skin state: a randomized, doubleblind, placebocontrolled, crossover trial. J Clin Biochem Nutr 65(4):52-58

Tang L, Zhang YX, Hutchinson CR (1994) Amino acid catabolism and antibiotic synthesis: valine is a source of precursors for macrolide 
biosynthesis in Streptomyces ambofaciens and Streptomyces fradiae. J Bacteriol 176(19):6107-6119

Tang CH, Ten Z, Wang XS, Yang XQ (2006) Physicochemical and functional properties of hemp (Cannabis sativa $\mathrm{L}$.) protein isolate. J Agric Food Chem 54(23):8945-8950

Thornfeldt C (2005) Cosmeceuticals containing herbs: fact, fiction, and future. Dermatol Surg 31(7 Pt 2):873-881

Toghrol F, Daneshpejouh H (1974) Estimation of free amino acids, protein and amino acid compositions of cumin seed (Cuminum cyminum) of Iran. J Trop Pediatr 20(3):109-111

Verdier-Sévrain S, Bonté F (2007) Skin hydration: a review on its molecular mechanisms. J Cosmet Dermatol 6(2):75-82

World Health Organization (WHO) (2013) WHO traditional medicine strategy 2014-2023. World Health Organization, pp 1-76

Wu G (2009) Amino acids: metabolism, functions, and nutrition. Amino Acids 37(1):1-17

Yimer EM, Tuem KB, Karim A, Ur-Rehman N, Anwar F (2019) Nigella sativa L. (Black Cumin): a promising natural remedy for wide range of illnesses. Evid Based Complement Altern Med 2019:1528635
Zeng F, Ou J, Huang Y, Li Q, Xu G, Liu Z, Yang S (2015) Determination of 21 free amino acids in fruit juices by HPLC using a modification of the 6-aminoquinolyl- $N$-hydroxysuccinimidyl carbamate (AQC) method. Food Anal Methods 8(2):428-437

Zhao X, Yang ZB, Yang WR, Wang Y, Jiang SZ, Zhang GG (2011) Effects of ginger root (Zingiber officinale) on laying performance and antioxidant status of laying hens and on dietary oxidation stability. Poult Sci 90(8):1720-1727

Ziegler J, Hussain H, Neubert RHH, Abel S (2019) Sensitive and selective amino acid profiling of minute tissue amounts by HPLC/electrospray negative tandem mass spectrometry using 9-fluorenylmethoxycarbonyl (Fmoc-Cl) derivatization. Methods Mol Biol 2030:365-379

Zou Y, Ma K, Tian M (2015) Chemical composition and nutritive value of hot pepper seed (Capsicum annuum) grown in Northeast Region of China. Food Sci Technol 35(4):659-663

Publisher's Note Springer Nature remains neutral with regard to jurisdictional claims in published maps and institutional affiliations. 